\title{
Emergency control algorithm for maintaining power stability based on Newton's method
}

\author{
G. S. Shabalin, P. V. Chusovitin, A. V. Pazderin \\ \& V. A. Tashchilin \\ Department of Automated Electrical Systems, Ural Federal University \\ named after the first President of Russia B. N. Yeltsin, Russia
}

\begin{abstract}
The problem of stability boundary evaluation for the current power system state is of paramount importance for power system operation. In addition, maintaining stability after large scale disturbances has come to the fore in recent years. This paper presents the algorithm, which allows us to both evaluate the stability boundary of a power system and to calculate emergency control actions for maintaining stability in the case of blackout. The algorithm is based on Newton's method for solving optimization problems. There are a number of emergency actions algorithms in literature, but most of them use heuristic rules. On the contrary, the proposed method has a reasonable analytical background. Thus, having an adequate power system model, the proposed method is able to calculate more accurate control actions. The paper demonstrates the very basic idea of the approach with the simplest example.

Keywords: feasible boundary evaluation, power system stability, Newton's method, Jacobian matrix.
\end{abstract}

\section{Introduction}

There are a number of methods for stability boundary evaluation. Most of them are based on linearization of the dynamic power system model [1-5] and evaluation of eigenproperties of the linearized model. Alternatively, feasibility boundary can be evaluated using mathematical programming techniques [6]. The proposed method is also based on mathematical programming, namely, Newton's method. Having a proper objective function, Newton's method can bring us directly to the feasibility boundary. The paper describes proper 
objective function formulation and provides some application examples of the proposed approach. Also some numerical features of the method are investigated.

\section{Objective function formulation}

Neglecting active resistance steady-state operation of the power system can be described as:

$$
\mathrm{P}_{\mathrm{T}}-\frac{\mathrm{U}_{\mathrm{c}} \cdot \mathrm{E}_{\mathrm{r}}}{\mathrm{x}_{\mathrm{c}}} \cdot \sin \delta=0,
$$

where $P_{\mathrm{T}}$ - the generator power, $\mathrm{MW}, U_{c}$ - the infinity bus voltage, $\mathrm{kV}, E_{\mathrm{\Gamma}}-$ the EMF of generator, $\mathrm{kV}, x_{\mathrm{c}}-$ the inductance of interconnection, Om, $\delta$ - the electrical angle between the infinity bus voltage and generator EMF.

Using (1) one can obtain objective function $\Phi(2)$ :

$$
\Phi=\left(P_{\mathrm{T}}-\frac{U_{c} \cdot E_{\mathrm{\Gamma}}}{x_{\mathrm{c}}} \cdot \sin \delta\right)^{2} .
$$

Figure 2 shows that one of $\Phi$ extrema coheres with the square of maximum active power. In this case, the problem can be formulated as the determining of $\Phi$ minimum. Obviously, the solving of the problem is connected with initial approximation issue. This question is of a great importance in the current investigation.

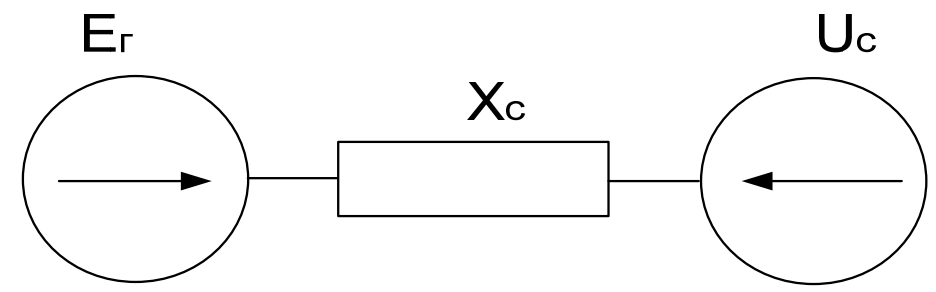

Figure 1: Scheme of a power system.

\section{Approach description and testing}

There are different ways to determine the function extremum. Newton's method is one of the most effective of them. In terms of our problem, it allows us to quickly find the function extremum. First and second order derivatives are shown below:

$$
\begin{gathered}
F=\frac{\partial \Phi}{\partial \delta}=-2 \cdot \frac{U_{c} \cdot E_{\Gamma}}{x_{\mathrm{c}}} \cdot \cos \delta \cdot\left(P_{\mathrm{T}}-\frac{U_{c} \cdot E_{\Gamma}}{x_{\mathrm{c}}} \cdot \sin \delta\right) ; \\
H=\frac{\partial^{2} \Phi}{\partial \delta^{2}}=2 \cdot\left(\frac{U_{c} \cdot E_{\Gamma}}{x_{\mathrm{c}}}\right)^{2} \cdot \cos \delta^{2} \\
+2 \cdot \frac{U_{c} \cdot E_{\Gamma}}{x_{\mathrm{c}}} \cdot \sin \delta \cdot\left(P_{\mathrm{T}}-\frac{U_{c} \cdot E_{\Gamma}}{x_{\mathrm{c}}} \cdot \sin \delta\right) .
\end{gathered}
$$


Table 1 illustrates the power system parameters.

Table 1: $\quad$ Power system parameters.

\begin{tabular}{|l|l|l|l|l|}
\hline & $\mathrm{x}_{\mathrm{c}}(\mathrm{Om})$ & $\mathrm{U}_{\mathrm{c}}(\mathrm{kV})$ & $\mathrm{P}_{\mathrm{T}}(\mathrm{MW})$ & $\mathrm{E}_{\mathrm{c}}(\mathrm{kV})$ \\
\hline parameter & 10 & 110 & 600 & 145 \\
\hline
\end{tabular}

In accordance with Newton's method approach one can form the recurrent equation as (5) and the conditions can be calculated by means of (6):

$$
\begin{aligned}
& \Delta X^{(i+1)}=H^{-1} F ; \\
& X^{(i+1)}=X^{(i+1)}+X^{(i)} .
\end{aligned}
$$

Using equation (3) and (4) and in accordance with data from table 1 Jacobian matrix (F) and Hessian matrix (H) can be obtained for initial approximations $\quad \delta^{(0)}=85^{\circ}=1,4835$ рад: $\quad F^{(0)}=274949,2, H^{(0)}=$ $-2104032,7$. In accordance with (5) and (6) the first step result can be calculated, namely $\Delta X^{(1)}=-0,08858=5,07^{\circ} ; X^{(1)}=90,07^{\circ}$.

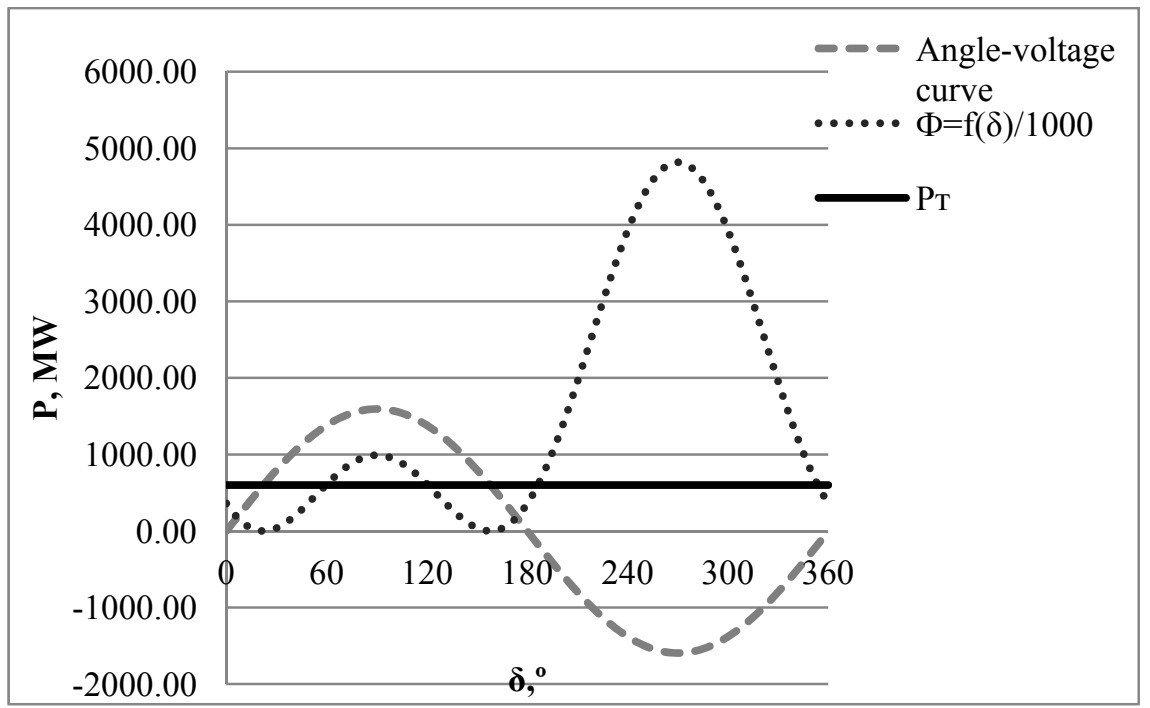

Figure 2: Angle-voltage curve and objective function.

As a result of using Newton's method and objective function (2) can lead to accurate and high-performance algorithm of determining active power maximum for a two-bus system to be developed.

As is shown in figure 3 , the area of initial conditions which converge to $\Phi$ $\left(\delta=90^{\circ}\right)$ maximum is interval $\left[53,85^{\circ} ; 126,15^{\circ}\right]$. To verify last point perform the calculation for $\delta^{(0)}=54^{\circ}=0,9425 \mathrm{rad}$ and $\delta^{(0)}=126^{\circ}=2,199 \mathrm{rad}$ as initial approximation in accordance with (3)-(6) and data from Table 1. The results are 


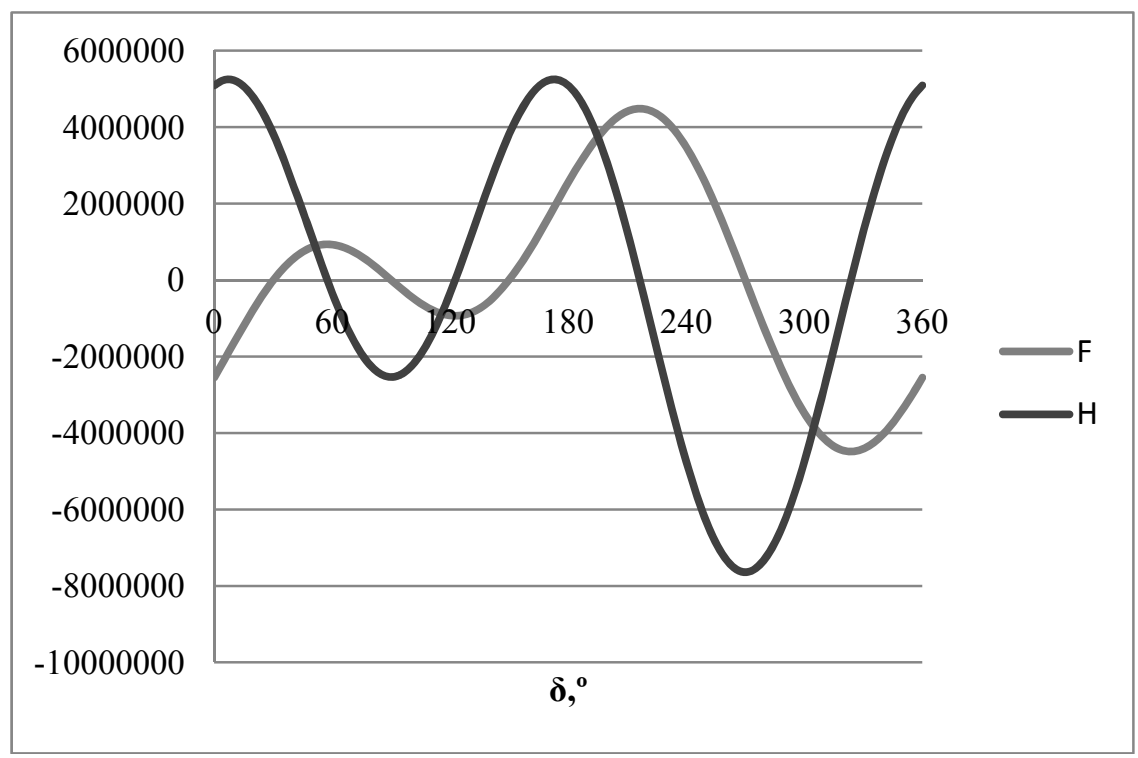

Figure 3: First and second derivative of objective function.

presented in Table 2. Obtained data illustrates that such initial approximations are inappropriate for calculation to converge to point $\mathrm{d}=90$ because of excessive step $\mathrm{dX}$. This step obviously should be limited. It can be achieved by additional constraint (7):

$$
\frac{F}{H} \leq 0,8
$$

The current constraint was obtained empirically. In this case, new area of proper initial conditions is $\left[64,3^{\circ} ; 115,7^{\circ}\right]$. Table 3 shows a calculation like table 2 but for a new area.

Investigate how converge initial condition area and constraints (7) change in depends upon different active power. When $\mathrm{P}=100$ a (7) should be equal or less than 1.1 and converge area is $-\left[57,9^{\circ} ; 122,1^{\circ}\right]$. When $\mathrm{P}=100$ a (7) should be equal or less than 0.31 and converge area is $-\left[81,2^{\circ} ; 98,8^{\circ}\right]$. Consequently area of proper initial approximation can be easily obtained for almost all points satisfied constraints (7) with a not greater than 0.3 and belonged to interval $\left[81,2^{\circ} ; 98,8^{\circ}\right]$ and then feasibility boundary can be estimated.

It is also necessary to discuss the situation, when $\mathrm{P}_{\mathrm{T}}>\mathrm{P}_{\max }$. In this case $\Phi$ function changes, it has only two extrema under estimation of initial approximation at $\left(0^{\circ} ; 180^{\circ}\right)$. Actually number of step is determined by number of initial approximations. Constraint (7) allows us to decrease the step quantity twice. In case $\mathrm{P}_{\mathrm{T}}>\mathrm{P}_{\max }$ been under consideration value of $\Phi$ for $\delta=90^{\circ}$ is square of difference between turbine power and maximum of power-angle curve.

Return to (1), no doubt it is nodal-voltage equation for generator node neglecting the active resistance. There is one small difference, namely, using 
Table 2: Proper initial approximation area verification (zero active resistance).

\begin{tabular}{|c|c|c|c|c|c|l|}
\hline $\begin{array}{c}\text { Initial } \\
\text { approximation }\end{array}$ & $\mathrm{F}^{(1)}$ & $\mathrm{H}^{(1)}$ & $\begin{array}{c}\Delta \mathrm{X}^{(1)} \\
(\mathrm{rad})\end{array}$ & $\begin{array}{c}\mathrm{X}^{(1)} \\
(\mathrm{rad})\end{array}$ & $\mathrm{X}^{(1)}\left(^{\circ}\right)$ & Convergence \\
\hline $\begin{array}{c}\delta^{(0)} \\
=0,9425 \mathrm{rad}\end{array}$ & 1294491 & $-23835,4$ & $-54,31$ & 55,25 & 285,6 & $\begin{array}{l}\text { To } 270^{\circ} \text { for } \\
3 \text { iteration }\end{array}$ \\
\hline $\begin{array}{c}\delta^{(0)} \\
=0,9425 \mathrm{rad}\end{array}$ & -1294491 & $-23835,4$ & 54,31 & 56,51 & $-2,22$ & $\begin{array}{l}\text { To } 22,1^{\circ} \text { for } \\
3 \text { iteration }\end{array}$ \\
\hline
\end{tabular}

Table 3: Proper initial approximation area verification (nonzero active resistance).

\begin{tabular}{|c|c|c|c|c|c|c|}
\hline $\begin{array}{c}\text { Initial } \\
\text { approximation }\end{array}$ & $\mathrm{F}^{(1)}$ & $\mathrm{H}^{(1)}$ & $\begin{array}{l}\Delta X^{(1)} \\
(\text { рад) }\end{array}$ & $\begin{array}{c}\mathrm{X}^{(1)} \\
\text { (рад) }\end{array}$ & $\begin{array}{l}X^{(1)} \\
\left({ }^{\circ}\right)\end{array}$ & Convergence \\
\hline $\begin{array}{c}\delta^{(0)} \\
=1,122 \mathrm{rad}\end{array}$ & 1158184 & -1449669 & $-0,799$ & 1,921 & 110,1 & $\begin{array}{l}\text { To } 90^{\circ} \text { for } \\
3 \text { iteration }\end{array}$ \\
\hline $\begin{array}{c}\delta^{(0)} \\
=2,053 \mathrm{rad}\end{array}$ & - & -1449669 & 0,799 & 1,254 & 71,85 & $\begin{array}{l}\text { To } 90^{\circ} \text { for } \\
3 \text { iteration }\end{array}$ \\
\hline
\end{tabular}

EMF except for node voltage. But this difference obviously has a negligible influence, for calculation presented above EMF can be easily replace by node voltage. In this case (1) comes to (8) and (2) comes to (9).

$$
\mathrm{E}_{\mathrm{r}}^{2} \cdot \mathrm{y}_{11} \cdot \cos \psi_{11}+\mathrm{U}_{\mathrm{c}} \cdot \mathrm{E}_{\mathrm{\Gamma}} \cdot \mathrm{y}_{12} \cdot \cos \left(\psi_{12}-\delta\right)=-\mathrm{P}_{\mathrm{T}},
$$

where $\mathrm{y}_{11}$ - absolute of generator node self-conductance; $\mathrm{y}_{12}$ - absolute of connection conductance between generator and infinity bus. psi11 - angle of self-conductivity; $\psi_{11}$ - angle of self-conductivity; $\psi_{12}$ - angle of connection conductivity respectively;

$$
\Phi=\left(E_{\Gamma}^{2} \cdot y_{11} \cdot \cos \psi_{11}+U_{c} \cdot E_{\Gamma} \cdot y_{12} \cdot \cos \left(\psi_{12}-\delta\right)+P_{T}\right)^{2} .
$$

$\mathrm{H}$ and $\mathrm{F}$ in this case can be evaluated by means of (10) and (11)

$$
\begin{gathered}
F=\frac{\partial \Phi}{\partial \delta}=2 \cdot U_{c} \cdot E_{\Gamma} \cdot y_{12} \cdot \\
\sin \left(\psi_{12}-\delta\right) \cdot\left(\mathrm{E}_{\Gamma}^{2} \cdot \mathrm{y}_{11} \cdot \cos \psi_{11}+\mathrm{U}_{\mathrm{c}} \cdot \mathrm{E}_{\Gamma} \cdot \mathrm{y}_{12} \cdot \cos \left(\psi_{12}-\delta\right)+\mathrm{P}_{\mathrm{T}}\right) ; \\
H=\frac{\partial^{2} \Phi}{\partial \delta^{2}}=2 \cdot U_{c} \cdot E_{\Gamma} \cdot y_{12} \cdot\left(-\cos \left(\psi_{12}-\delta\right)\right) \cdot \\
\cdot\left(\mathrm{E}_{\Gamma}^{2} \cdot \mathrm{y}_{11} \cdot \cos \Psi_{11}+\mathrm{U}_{\mathrm{c}} \cdot \mathrm{E}_{\Gamma} \cdot \mathrm{y}_{12} \cdot \cos \left(\psi_{12}-\delta\right)+\mathrm{P}_{\mathrm{T}}\right)+2 \cdot\left(U_{c} \cdot E_{\Gamma} \cdot y_{12} \cdot\right. \\
\left.\cdot \sin \left(\psi_{12}-\delta\right)\right)^{2} .
\end{gathered}
$$

Table 4 shows the power system parameters including active resistance.

Table 4: $\quad$ Power system parameters with nonzero active resistance.

\begin{tabular}{|l|l|l|l|l|l|}
\hline & $\mathrm{x}_{\mathrm{c}}(\mathrm{Om})$ & $\mathrm{R}_{\mathrm{c}}(\mathrm{Om})$ & $\mathrm{U}_{\mathrm{c}}(\mathrm{kV})$ & $\mathrm{P}_{\mathrm{T}}(\mathrm{MW})$ & $\mathrm{E}_{\mathrm{c}}(\mathrm{kW})$ \\
\hline parameter & 10 & 3 & 110 & 800 & 145 \\
\hline
\end{tabular}


The results of voltage-angle function maximum computation by means of $\Phi$ function for operation conditions presented in table 4 are presented in table 5 . The table gives information about step number and convergence success. Graphical illustration of $\Phi, \mathrm{F}$ and $\mathrm{H}$ are presented in figures 4 and 5. First and

Table 5: Computation results.

\begin{tabular}{|l|l|l|l|l|}
\hline № & \multicolumn{1}{|c|}{$\begin{array}{c}\text { Initial } \\
\text { approximation }\left({ }^{\circ}\right)\end{array}$} & $\mathrm{H}^{(0)} / \mathrm{F}^{(0)}$ & $\begin{array}{c}\text { The number of } \\
\text { iterations }\end{array}$ & $\begin{array}{c}\text { Convergence } \\
\text { to point (MW) }\end{array}$ \\
\hline 1 & $90^{\circ}$ & $-0,336$ & 2 & $\mathrm{P}_{\max }=2106,4$ \\
\hline 2 & $80^{\circ}$ & $-0,72$ & 3 & $\mathrm{P}_{\max }=2106,4$ \\
\hline 3 & $76^{\circ}$ & $-1,03$ & 4 & $\mathrm{P}_{\max }=2106,4$ \\
\hline 4 & 75 & $-1,14$ & 12 & $\mathrm{P}_{\max }=2106,4$ \\
\hline 5 & 70 & $-2,315$ & 4 & $\begin{array}{l}\mathrm{P}=800 \\
\text { (instability point) }\end{array}$ \\
\hline 6 & 110 & 0,0579 & 2 & $\mathrm{P}_{\max }=2106,4$ \\
\hline 7 & 120 & 0,253 & 2 & $\mathrm{P}_{\max }=2106,4$ \\
\hline 8 & 130 & 0,552 & 3 & $\mathrm{P}_{\max }=2106,4$ \\
\hline 9 & 135 & 0,825 & 3 & $\mathrm{P}_{\max }=2106,4$ \\
\hline 10 & 137,5 & 1,041 & 5 & $\mathrm{P}_{\max }=2106,4$ \\
\hline 11 & 140 & 1,374 & 7 & $\begin{array}{l}\mathrm{P}=800 \\
\text { (stability point) }\end{array}$ \\
\hline
\end{tabular}

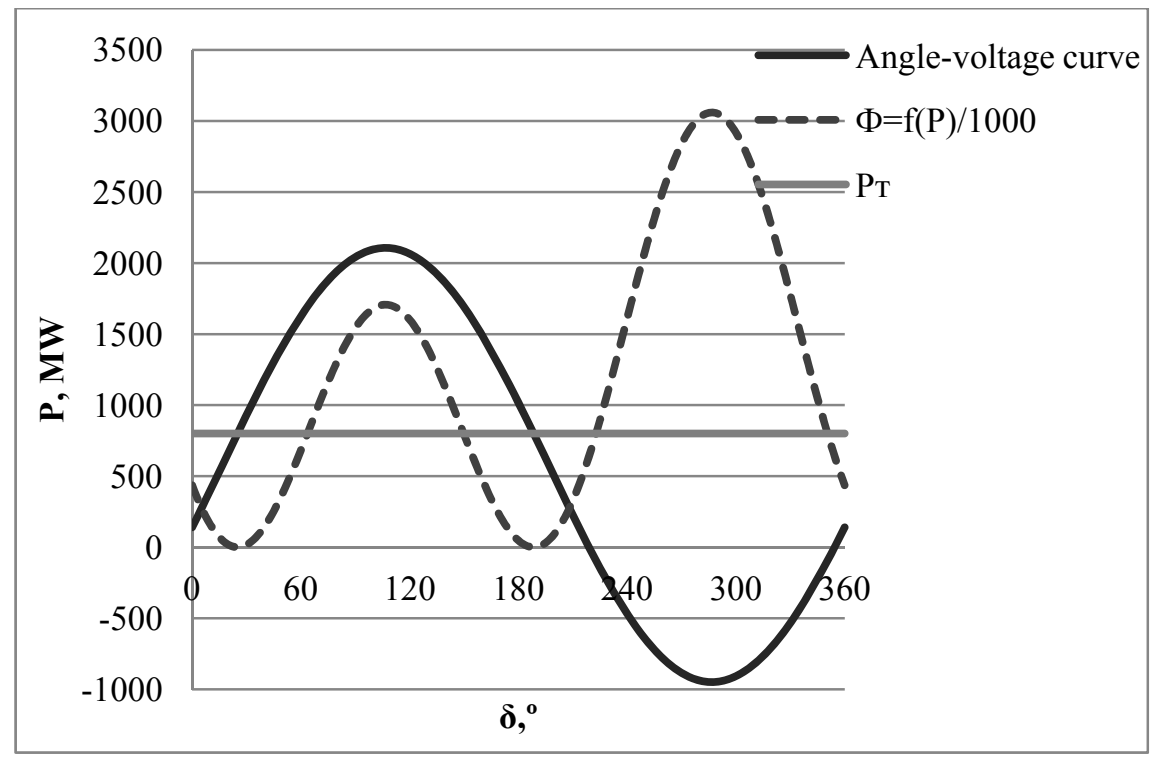

Figure 4: Angle-voltage curve and objective function for nonzero active resistance. 


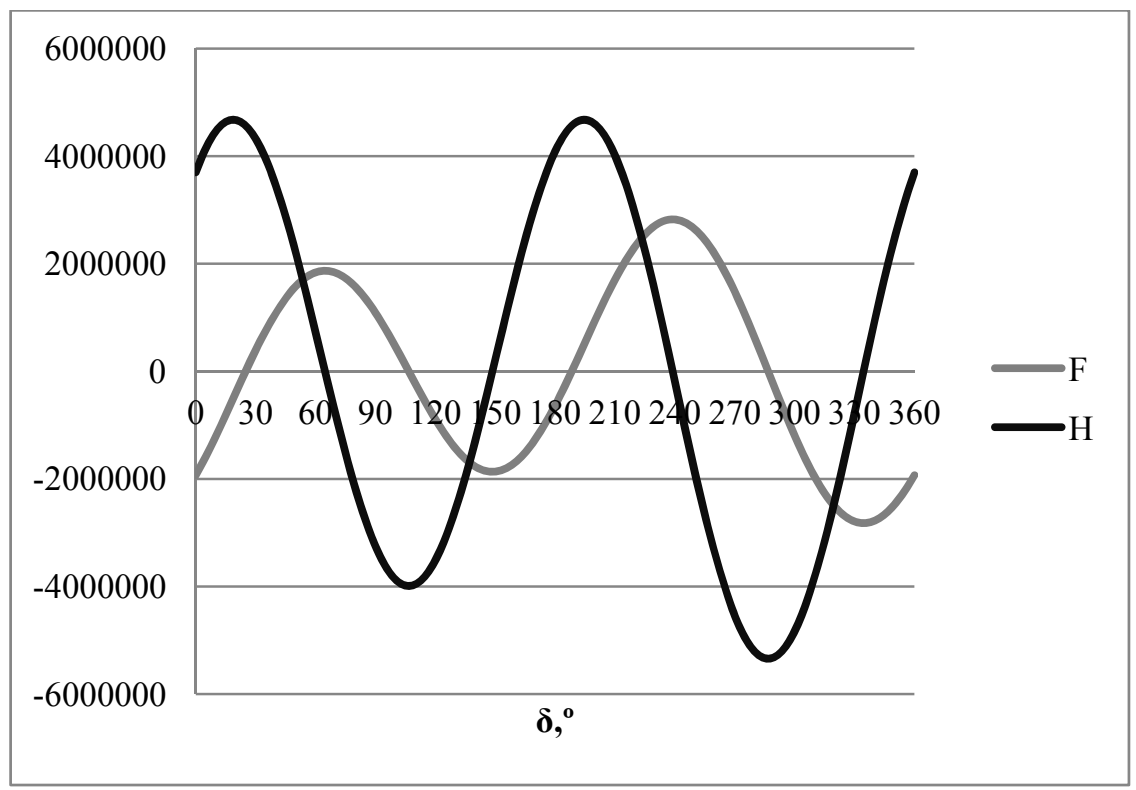

Figure 5: First and second order derivative of objective function for nonzero active resistance.

second derivative follow maximum objective function, area of proper initial approximations moves similar.

Data from table 5 shows that Newton's method approaching for proper initial approximation permits accurate and fast to determine the maximum of anglevoltage curve. Constraints for initial approximation mentioned above take place for nonzero active resistance case.

\section{Conclusion}

The approach for feasibility boundary evaluation presented in the paper can be further developed for application to interconnected power systems. Software on the proposed approach will give power system operators new features for reliable power system operation. Another way for developing algorithm is designing procedure for indentifying Jacobi and Hesse matrices similar to [7, 8].

\section{References}

[1] T. Jain, S.N. Singh, S.C. Srivastava, "Assessment of oscillatory stability constrained available transfer capability", Electrical Power and Energy Systems 31 (2009), pp. 192-200.

[2] Bathiya Jayasekara and Udaya D. Annakkage, "Derivation of an Accurate Polynomial Representation of the Transient Stability Boundary", IEEE 
transactions on Power Systems, vol. 21, no. 4, pp. 1856-1863, November 2006.

[3] Florin CIAUSI, Mircea EREMIA, "Steady-State stability limit identification for Large Power Systems", U.P.B. Sci. Bull., series C, vol. 72, iss. 1, pp. 201-209, 2010.

[4] Joost Rommes, Nelson Martins and Francisco Damasceno Freitas, "Computing Rightmost Eigenvalues for Small-Signal Stability Assessment of Large-Scale Power Systems", IEEE Transactions on Power Systems, vol. 25, no. 2, pp. 929-938, May 2010.

[5] Jian Ma, Zhao Yang Dong and Pei Zhang, "Comparison of BR and QR Eigenvalue Algorithms for Power System Small Signal Stability Analysis”, IEEE Transactions on Power Systems, vol. 21, no. 4, pp. 1848-1855, November 2006.

[6] Luis A. Ll. Zarate, Carlos A., Jose Luis Martinez Ramos, "Fast Computation of Voltage Stability Security Margins Using Nonlinear Programming Techniques", IEEE Transactions on Power Systems, vol. 21, no. 1, pp. 1927, February 2006.

[7] P. Chusovitin, "Transient Prediction and Small-Signal Stability Analysis using PMU-based Power System Identification", IASTED Asian Conference Power and Energy Systems. 2012, Phuket, Thailand.

[8] P. Chusovitin, A. Pazderin, "Implementation of Power System Model Identification for Locating In-phase Generators", 3rd IEEE PES Innovative Smart Grid Technologies Europe (ISGT Europe,) 2012, Berlin. 